\title{
Homogeneously sized groups increase aggressive interaction and affect social stress in Thai strain Nile tilapia (Oreochromis niloticus)
}

Tatiana Nunes Barreto, Camila Nomura Pereira Boscolo \& Eliane Gonçalvesde-Freitas

To cite this article: Tatiana Nunes Barreto, Camila Nomura Pereira Boscolo \& Eliane Gonçalvesde-Freitas (2015) Homogeneously sized groups increase aggressive interaction and affect social stress in Thai strain Nile tilapia (Oreochromis niloticus), Marine and Freshwater Behaviour and Physiology, 48:5, 309-318, DOI: 10.1080/10236244.2015.1070478

To link to this article: https://doi.org/10.1080/10236244.2015.1070478

Published online: 07 Aug 2015.

Submit your article to this journal ¿

山 Article views: 53

View Crossmark data ¿

Citing articles: 5 View citing articles $\square$ 


\section{Homogeneously sized groups increase aggressive interaction and affect social stress in Thai strain Nile tilapia (Oreochromis niloticus)}

Tatiana Nunes Barreto ${ }^{\mathrm{a}}$, Camila Nomura Pereira Boscolo ${ }^{\mathrm{a}, \mathrm{b} *}$ and Eliane Gonçalves-de-Freitas ${ }^{\mathrm{a}, \mathrm{b}}$

${ }^{a}$ Departamento de Zoologia e Botânica, Universidade Estadual Paulista, UNESP, São José do Rio Preto, Brazil; ${ }^{b}$ Centro de Aquicultura da UNESP, São José do Rio Preto, Brazil

(Received 11 February 2015; accepted 29 June 2015)

Social fish raised in farms are usually kept in groups of similar-sized individuals. However, social animals of similar size typically have similar fighting ability, which increases aggressive interaction for social rank establishment, as well as social stress. We compared Thai strain Nile tilapia fish, Oreochromis niloticus (L.), held under two treatments: (1) The Homogeneous one, with five adult male fish of similar size and (2) the Heterogeneous treatment with five adult males of different sizes. We recorded the frequency of aggressive interactions and checked social stability and stress levels (cortisol) after five days in the groups. Grouping similar sized Thai Nile tilapia increased the aggressive interactions and delayed rank stability with increased body injuries as a consequence. Homogeneous-sized individuals showed a similar level of stress while heterogeneous-sized individuals showed different stress levels with dominants being more stressed than subordinates. The data indicate that the practice of selecting fish of similar size in aquaculture management could reduce the welfare of social fish and that the effect is observed in different lineages.

Keywords: Nile tilapia Oreochromis niloticus; culture; size selection; aggression; stress; welfare

\section{Introduction}

Management practices in aquaculture production systems can cause some negative effects on fish welfare because most of them are interwoven with several types of stressors (e.g., Pickering et al. 1982; Barton \& Iwama 1991; Wendelaar Bonga 1997). One of those widespread practices is the selection of fish of similar size for commercial and livestock purposes (e.g., Slavík et al. 2011). Although this is desirable for product standardization, the procedure of sorting animals by size causes handling stress (Ellis et al. 2004) and, for some social fish species, can also increase aggressive interactions (Ang \& Manica 2010; Boscolo et al. 2011; Alonso et al. 2012). Negative effects arise in this case because animals of similar size often have the same fighting ability. This translates to a similar chance of winning a contest (Enquist \& Leimar 1983) so that contests can last longer and delay the establishment of hierarchies which in turn increases the social stress for the fish (Koops \& Grant 1992; Ang \& Manica 2010).

\footnotetext{
*Corresponding author. Email: nomuracamila@yahoo.com.br
} 
Size difference is an important visual signal providing information for assessing fighting ability in fishes, and by keeping similarly sized fish together, the naturally selected social rank signals can be reduced or removed. Boscolo et al. (2011) have already demonstrated such negative effects for Nile tilapia (GIFT strain) in which groups formed by similar-sized fish showed increased aggressive interactions and also social instability (rank-order reversals). The authors found no association between the behavioral changes and the increased stress levels when all individuals in the group were considered. They found, however, differences among social ranks in which the dominant fish were more stressed than the subordinates only in the groups of different sizes.

The GIFT Nile tilapia is a product of artificial selection for fast growth and so it is plausible to suppose that some influence of this management selection could be acting on the aggressive behavior of the fish and magnifying the effects of size grouping conditions. Several studies have shown that the genetic bases of aggressive behavior in fish may change according to strains and domestication factors (Vaz-Serrano et al. 2011). Domesticated Siamese fighting fish, Betta splendens, are more aggressive, for instance than wild ones (Verbeek et al. 2007). Domesticated zebrafish shows a reduced avoidance of predators compared to a wild zebrafish (Drew et al. 2012). Studies on different fish strains are thus important because the artificial selection of certain features may also select for other characteristics such as aggression and stress resilience (Pottinger et al. 1994; Schjolden \& Winberg 2007). There is, however, a lack of studies that focus on the behavior of different Nile tilapia strains. Among several domesticated tilapias, the Thai strain is less modified by artificial selection than the GIFT strain (Eknath et al. 2007). If aggressiveness is correlated with growth characteristics, it is possible that Thai Nile tilapia show a less intense response to aggression and social stress following size classification than other tilapias strains such as GIFT. In this study, we tested the effect of grouping homogeneous-sized animals on aggressive behavior and social stress in Thai Nile tilapia and examined whether such aggressive levels are a matter of lineage or whether it is a common response for Nile tilapia.

\section{Methods}

\section{Animals and housing conditions}

We used adult sex-inversed males of Nile tilapia Oreochromis niloticus (L.), Thai strain. Fish ranging from 50 to $120 \mathrm{~mm}$ standard length (SL) were kept together in 500-L indoor stock-tanks (ca. 1 fish $10 \mathrm{~L}^{-1}$ ) for 20 days for acclimation before the experiment began. The tanks contained dechlorinated water kept at $27{ }^{\circ} \mathrm{C}$ and $12 \mathrm{~L}: 12 \mathrm{D}$ light regime. The water quality was maintained by external biological filters (filtering $400 \mathrm{~L} \mathrm{~h}^{-1}$ ), and the tanks were cleaned once a week. Food (commercial pellets for tropical fish, 32\% Crude Protein; Guabi-Pira/Brazil-http://www.guabi.com.br/rc/peixes/ produtos.asp) was provided twice a day to satiation.

\section{Experimental design}

We compared the effect of grouping animals of similar size on the aggressive behavior, social stability, and social stress in adult Nile tilapia males, Thai strain. We setup two treatments by size similarity $(N=12$ each), named homogeneous and heterogeneous, based on a study by Boscolo et al. (2011). The homogeneous treatment (HO) had five 
same-sized males (HO: mean \pm S.E.: SL: $105.90 \pm 5.90 \mathrm{~mm}$, range $100.0-105.0 \mathrm{~mm}$ and coefficient of variation $(\mathrm{CV}): 17.39 \pm 4.66 \%$; weight $(\mathrm{W}): 36.78 \pm 6.25 \mathrm{~g}$, range $36.0-43.0 \mathrm{~g}$ and $\mathrm{CV}: 69.87 \pm 26.67 \%$ ). The heterogeneous treatment (HE) had five males of different sizes (HE: mean \pm S.E.: SL: $104.20 \pm 13.30 \mathrm{~mm}$, range 80.0 $120.0 \mathrm{~mm}$ and $\mathrm{CV}: 134.97 \pm 20.19 \%$; W: $35.86 \pm 14.34 \mathrm{~g}$, range $35.0-50.0 \mathrm{~g}$ and $\mathrm{CV}$ : $414.08 \pm 69.86 \%$ ). This size arrangement guaranteed a similar density and biomass between treatments so that only the difference in between-fish size varied. The animals were grouped for five days during which the levels of aggression (frequency of aggressive interaction), social stability (changes in rank order), and social stress (cortisol levels) were recorded.

\section{Experimental aquaria}

Animals were anesthetized with benzocaine $\left(9 \mathrm{mg} \mathrm{L}^{-1}\right)$, measured, weighed, and individually identified by Visual Implant Elastomer (V.I.E tags) before being assigned to one of the treatments (HO or HE). The experimental aquaria had $60 \times 60 \times 40 \mathrm{~cm}$ $(\sim 140 \mathrm{~L})$, with three sides covered by blue plastic to block visual contact between fish in adjacent aquaria. Blue was chosen because it reduces cortisol levels in the Nile tilapia (Volpato \& Barreto 2001; Maia \& Volpato 2013). The water temperature was set to $27^{\circ} \mathrm{C}$ and the photoperiod to $12 \mathrm{~L}: 12 \mathrm{D}(7: 00-19: 00 \mathrm{~h})$. Fish were fed a standard ration for tropical fish (as described in topic Animals and housing conditions) in an amount of $3 \%$ of biomass, in two daily intervals (at 8:00 and 17:00 h).

\section{Behavioral records}

Fish were video-recorded $\left(10 \mathrm{~min}_{\mathrm{day}}{ }^{-1}\right)$ to record the aggressive interactions and identify the social position of fish for subsequent quantification. Large numbers of fish in aquaculture groups impair individual observations. We therefore used groups of five fish, which was the maximum in which we could identify social rank and individual behavior (as used by Boscolo et al. (2011)).

We recorded fish behavior from the second day between 09:00 and 10:30 h using camcorders placed on tripods in front of the experimental aquaria. An observer did not stay in the room during the recording sessions to avoid an observer effect. The agonistic interactions were divided into attacks (overt fights such as mouth fighting, nipping, lateral fighting, and tail beating) and displays (such as chase and threat) as described by Carvalho and Gonçalves-de-Freitas (2008) and Boscolo et al. (2011) for Nile tilapia.

\section{Social rank and social stability}

The social rank was defined by dominance index (DI: number of attacks emitted/total number of attacks in the group), as done by Gonçalves-de-Freitas et al. (2008) and Boscolo et al. (2011) for O. niloticus, GIFT strain. DI varies from 0 to 1.0 with the dominant DI higher than the subordinate one. This allowed us to identify a linear hierarchy, with five ranked individuals. The social instability was assessed through social position reversals over time. The DI of the 5 fish in each group was compared among days using the Spearman correlation coefficient $\left(r_{\mathrm{s}}\right)$. This analysis was based on the criteria of Oliveira and Almada (1996) and those groups showing $r \geq 0.70$ were considered stable, (i.e., with minimal changes in daily DI). 


\section{Social stress and cortisol assay}

Blood was sampled before grouping and at the end of the 5th day of grouping for a cortisol assay. Fish were caught from the stock-tank at the same time and were all anesthetized by immersion on benzocaine (Sigma/Aldrich/China $9 \mathrm{mg} \mathrm{L}^{-1}$ ). All fish lost body equilibrium, and their breathing rates slowed one minute after immersion in benzocaine which allowed blood samples to be taken quickly. The entire procedure, from when the researchers approached the aquarium to the end of all blood sampling, took less than $2 \mathrm{~min}$. It was devised to ensure that cortisol levels were not elevated during blood sampling (e.g., Pottinger 2008). Blood was taken from the tail vein between 10:30 and 11:00 am to avoid circadian variations. Blood was centrifuged at $3.000 \mathrm{rpm}$ for $10 \mathrm{~min}$; plasma was gathered and placed in capped 1.5-ml polypropylene (Eppendorf) tubes, and frozen at $-20^{\circ} \mathrm{C}$. Plasma cortisol levels were assayed later by ELISA - Enzyme-Linked Immunosorbent Assay validated for Thai Nile tilapia, according to the methods described by Brown et al. (2004). This is a well-established method applicable to fish (McKenzie et al. 2012).

\section{Statistical analysis}

All data were tested and conformed to criteria for normality and homoscedasticity. We then compared the frequency of attacks and displays between treatments using unpaired $t$ test. The initial and final cortisol levels of groups (mean from five individuals) were compared by a repeated measures ANOVA with treatments (HO vs. HE) as categorical factors and periods (before vs. after grouping) as the repeated measures. The social stability was assessed by the number of stable vs. unstable groups within each treatment with a Binomial test (Goodman 1965). The final concentration of plasma cortisol was compared with the rank of a fish recorded in the last day of grouping by a one-way ANOVA. Fisher's LSD was applied as a post hoc test. The significance level was set at $p \leq 0.05$. All statistical tests and assumptions were based on Zar (1999).

\section{Ethical clearance}

This study was conducted in agreement with the guidelines of the National Council for the Control of Animal Experimentation (Conselho Nacional de Controle de Experimentação Animal, CONCEA, Brazil) and was approved by the Ethical Committee of Animal Experimentation of the Universidade Estadual Paulista (UNESP), São José do Rio Preto, SP, Brazil (permit 008/09).

\section{Results}

\section{Aggressive behavior and social stability}

The frequency of attacks was higher in the HO treatment (unpaired $t$ test; $t_{(22)}=2.45$, $p=0.02$; Figure $1(\mathrm{~A})$ ). There was no difference in the frequency of displays between treatments (unpaired $t$ test; $t_{(22)}=1.92, p=0.07$; Figure $1(\mathrm{~B})$ ). By analyzing the number of socially unstable $\left(r_{\mathrm{s}}<0.70\right)$ and stable $\left(r_{\mathrm{s}}>0.70\right)$ relationships in each treatment, we observed that more replicates in the HE treatment remained stable following the first comparison (Binomial test, $p>0.05$; Table 1). In the $\mathrm{HO}$ treatment, more replicates became stable only in the last comparison - between the 3rd and 4th day of grouping (Binomial test, $p<0.05$; Table 1). We observed loss of scales and some injuries on the bodies of fish in the HO treatment, but not in the HE treatment. 

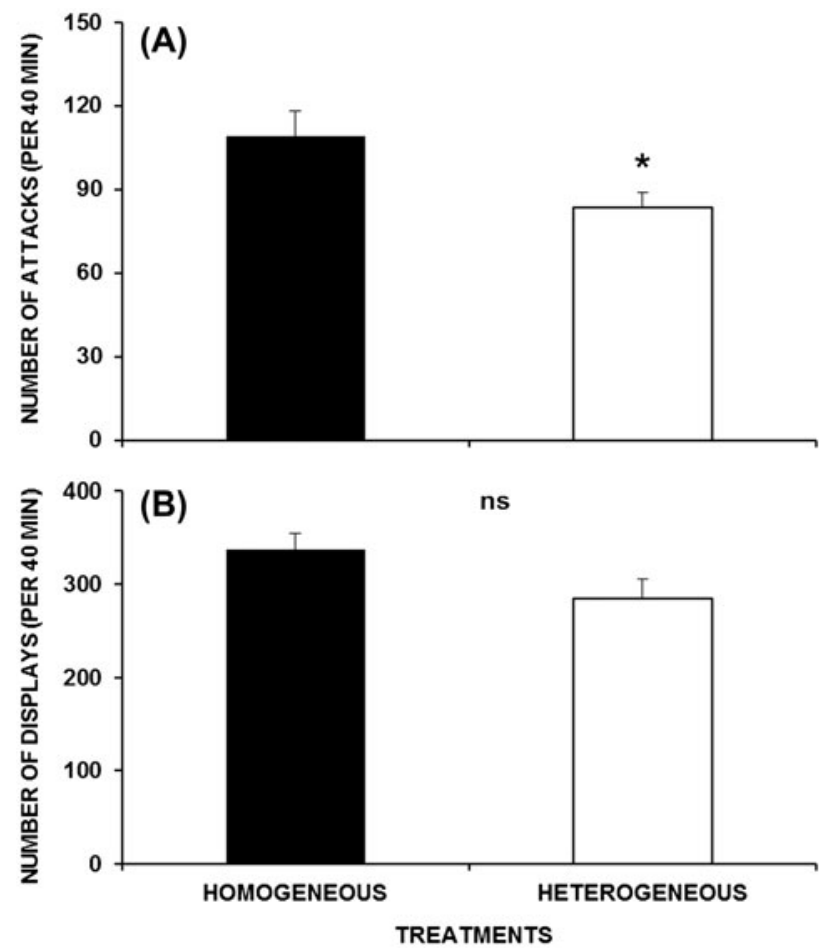

Figure 1. Number of attacks (A) and displays (B) over 4 days of observations in homogeneous and heterogeneous treatments $(N=12$ each $)$.

Notes: Asterisk indicates a significant difference between treatments after the unpaired $t$ test. Note different scales in Figures A and B. Data are showed as mean \pm S.E.

Table 1. Frequency of replicates showing social hierarchy stability $\left(r_{\mathrm{s}} \geq 0.70\right)$ and instability $\left(r_{\mathrm{s}}<0.70\right)$.

\begin{tabular}{lccccc}
\hline & \multicolumn{2}{l}{$\begin{array}{l}\text { Homogeneous-sized } \\
\text { treatment }(N=12)\end{array}$} & & \multicolumn{2}{l}{$\begin{array}{l}\text { Heterogeneous-sized } \\
\text { treatment }(N=12)\end{array}$} \\
\cline { 2 - 3 } \cline { 5 - 6 } Observations & Unstable & Stable & & Unstable & Stable \\
\hline 1st to 2nd & 7 & 5 & & 2 & $10^{*}$ \\
2nd to 3rd & 4 & 8 & & 2 & $10^{*}$ \\
3rd to 4th & 1 & $11^{*}$ & & 2 & $10^{*}$ \\
\hline
\end{tabular}

*Means significant difference after Binomial test $(p<0.05)$.

\section{Cortisol levels}

There was no significant difference between the treatments for plasma cortisol levels when comparing the mean cortisol in the group (ANOVA for repeated measures: $F(1,108)=0.59, p=0.44)$. Cortisol levels before grouping were, however, higher than after grouping for both treatments (cortisol before grouping, mean \pm S.E.: HE $=65.78$ $\pm 5.0 ; \mathrm{HO}=73.09 \pm 4.90$; cortisol after grouping mean \pm S.E.: $\mathrm{HE}=36.93 \pm 3.51$; $\mathrm{HO}=38.38 \pm 2.66$; ANOVA for repeated measures: $F(1,108)=70.63, p<0.0001$; LSD, $p<0.0001)$. We analyzed the cortisol by rank on the last day but only in the 

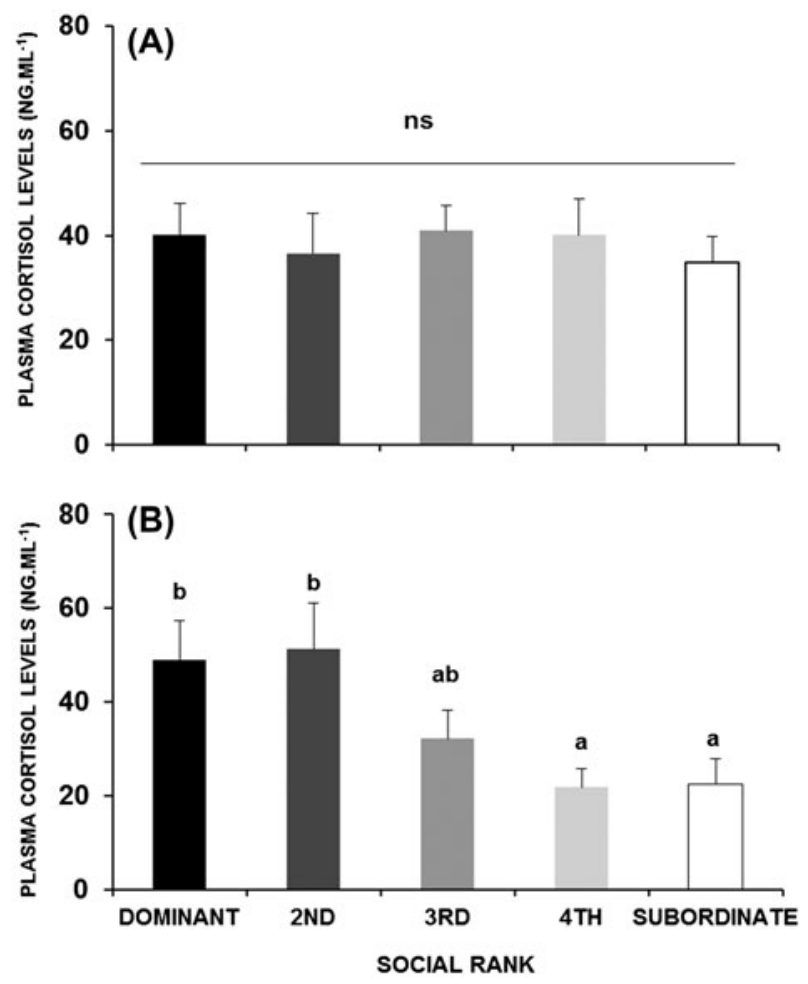

Figure 2. Mean $( \pm$ S.E. $)$ plasma cortisol levels in different social ranks in treatments $(N=10$ each) homogeneous (A) and heterogeneous (B).

Notes: Fish ranks are shown according to a decreasing dominance index with the dominant fish having the higher one. Bars followed by at least one different letter indicate a significant difference after one-way ANOVA plus Fisher's LSD post hoc test.

stable groups. We then compared 10 replicates from the HE treatment and 10 from the HO treatment, removing one that was unstable and another from which the plasma volume was insufficient for the cortisol assay. We observed no difference in plasma cortisol concentrations between ranks for the HO treatment (one-way ANOVA; $F(4,45)$ $=0.18, p=0.94$; Figure 2(A)), whereas in the HE treatment, we found differences (one-way ANOVA; $F(4,55)=3.34, p=0.017$; Figure 2(B)). The 1st and 2nd dominant animals in the rank showed similar cortisol levels $(p=0.83)$ and both showed higher cortisol than the 4 th and 5 th animal in the rank $(p<0.019)$. These last ranks were also similar between them $(p=0.95)$. The $3 \mathrm{rd}$ in the rank had similar cortisol levels to all other ranks $(p>0.09)$.

\section{Discussion}

In this study, we showed that by grouping similar-sized Thai Nile tilapia, the aggressive interactions increase and rank stability is delayed, with body injuries as a consequence. Homogeneous-sized individuals experience a similar level of social stress, while heterogeneous-sized individuals experience different levels of social stress, with dominant fish being more stressed than subordinate fish. 
In many fish groups, individuals fight aggressively until dominance is established (Nelissen 1985; Turner \& Huntingford 1986). Overt contests are reduced after that and replaced by displays that reinforce the social position of the fish (Johnsson et al. 2006) and reduce the chances of overt fights. Here, we found a higher frequency of agonistic interactions in the HO treatment indicating that grouping similar-sized fish increases readiness to fight. The higher frequency of attacks can be considered a consequence of the similar fighting ability of the animals, delaying hierarchy establishment (Enquist \& Jakobsson 1986). The establishment of social hierarchies can be an evolutionary solution to competition for limited resources (Sneddon et al. 2006) because it reduces energetic expenditure contests (Alvarenga \& Volpato 1995; Vollestad \& Quinn 2003; Ros et al. 2006) and risk of injuries and death (Johnsson et al. 2006). The lower the frequency of attacks, the higher the energy availability to spend on growth and other functions (Neat et al. 1998; Sloman et al. 2000; Castro et al. 2006; Johnsson et al. 2006). Boscolo et al. (2011) observed that homogeneous-sized groups of GIFT strain male Nile tilapia were more aggressive than heterogeneous-sized groups, suggesting that size homogeneity is a determining factor in different strains. Any protocol that increases aggression, as by culturing territorial fish is therefore likely to produce negative effects on the fish.

Social stability was observed in both treatments, but was achieved more quickly in the HE treatment. Again, the size homogeneity of animals was associated with a more intense and long-lasting competition. Because relative fighting ability is not purely defined by body size, other factors may have influenced the hierarchical establishment in the HO treatment. The delayed establishment of a stable hierarchy may be harmful to the animals because it increases aggressive interactions and thus the risk of injuries to the contestants (Johnsson et al. 2006) as we observed in this study. Such a risk seems to be dependent on the lineage because social establishment was not achieved in 5 days for similar size groups in GIFT strain (Boscolo et al. 2011). Thai Nile tilapia could thus be less affected by size classification management.

Despite the differences in aggressive behavior and the later hierarchical establishment in the HO treatment, cortisol levels were similar between treatments, contrary to our expectations, when considering all the fish in the group. We expected to find higher cortisol levels in the HO treatment due to a higher frequency of agonistic interactions because, according to Corrêa et al. (2003), agonistic interactions are associated with high concentrations of cortisol in Nile tilapia. However, we found association between hierarchical rank and cortisol.

Several studies have reported that subordinate fish are more stressed and show higher cortisol levels than dominant individuals (Fernandes \& Volpato 1993; Corrêa et al. 2003). We found, however, the opposite situation. The higher cortisol level found for dominant fish in the HE treatment may be a consequence of animals reinforcing their social position against the closest rank, and this could increase social stress (e.g., Sloman et al. 2008). On the other hand, subordinate animals tend to avoid agonistic interactions (Oliveira \& Almada 1996) and show lower cortisol levels. Then, although it is well established that subordinate fish have higher cortisol levels than dominants (Corrêa et al. 2003), most physiological studies are performed with pairs, and the subordinate is the only threatened fish. It is possible that in larger groups, the last in the rank is the last to be attacked, and thus, lower ranked fish might also be less stressed. Boscolo et al. (2011) studied similar large groups of male Nile tilapia, GIFT strain and observed that dominants were more stressed than subordinates in asymmetric groups, reinforcing the results found in this study. The data, therefore, indicate that practices of 
selecting fish by size during aquaculture management may reduce the welfare of social fish and the effect may be observed differently in different lineages.

\section{Acknowledgements}

We thank our colleagues in the Animal Behavior Laboratory for their assistance in data collection, maintenance of fish and relevant discussions on this manuscript; Msc Roselene S. Costa Ferreira and Carlos Eduardo de Souza for technical support. We also thank the Aquaculture Center of UNESP for donating fish.

\section{Disclosure statement}

No potential conflict of interest was reported by the authors.

\section{Funding}

This work was funded by CNPq proc. [grant number 479600/2008-2] (E. Gonçalves-de-Freitas); FAPESP proc. [scholarship number 2009/04690-6] (Barreto, T.N.).

\section{References}

Alonso F, Honji RM, Moreira R, Pandolfi M. 2012. Dominance hierarchies and social status ascent opportunity: anticipatory behavioral and physiological adjustments in a neotropical cichlid fish. Physiol Behav. 106:612-618.

Alvarenga CMD, Volpato GL. 1995. Agonistic profile and metabolism in alevins of the Nile tilapia. Physiol Behav. 57:75-80.

Ang TZ, Manica A. 2010. Unavoidable limits on group size in a body size-based linear hierarchy. Behav Ecol. 21:819-825.

Barton BA, Iwama GK. 1991. Physiological changes in fish from stress in aquaculture with emphasis on the response and effects of corticosteroids. Annu Rev Fish Dis. 1:3-26.

Boscolo CNP, Morais RN, Gonçalves-de-Freitas E. 2011. Same sized fish groups increase aggressive interaction of sex-reversed males Nile tilapia GIFT strain. Appl Anim Behav Sci. 135:154-159.

Brown J, Walker SE, Steinmain K. 2004. Endocrine Manual for the Reproductive Assessment of Domestic and Non-Domestics Species. Front Royal (VA): Conservation and Research Center, Smithsonianís National Zoological Park.

Carvalho TB, Gonçalves-de-Freitas E. 2008. Sex group composition, social interaction, and metabolism in the fish Nile tilapia. Braz J Biol. 68:807-812.

Castro N, Ros AFH, Becker K, Oliveira RF. 2006. Metabolic costs of aggressive behaviour in the Siamese fighting fish, Betta splendens. Aggressive Behav. 32:474-480.

Corrêa SA, Fernandes MO, Iseki KK, Negrão JA. 2003. Effect of the establishment of dominance relationships on cortisol and other metabolic parameters in Nile tilapia (Oreochromis niloticus). Braz J Med Biol Res. 36:1725-1731.

Drew RE, Settles ML, Churchill EJ, Williams SM, Balli S, Robison BD. 2012. Brain transcriptome variation among behaviorally distinct strains of zebrafish (Danio rerio). BMC Genomics. 13:1471-2164.

Eknath AE, Bentsen HB, Ponzoni RW, Rye M, Nguyen NH, Thodesen J, Gjerde B. 2007. Genetic improvement of farmed tilapias: composition and genetic parameters of a synthetic base population of Oreochromis niloticus for selective breeding. Aquaculture. 273:1-14.

Ellis T, James JD, Stewart C, Scott AP. 2004. A non-invasive stress assay based upon measurement of free cortisol released into the water by rainbow trout. J Fish Biol. 65:1233-1252. 
Enquist M, Jakobsson S. 1986. Decision making and assessment in the fighting behaviour of Nannacara anomala (Cichlidae, Pisces). Ethology. 72:143-153.

Enquist M, Leimar O. 1983. Evolution of fighting behaviour: decision rules and assessment of relative strength. J Theor Biol. 102:387-410.

Fernandes MO, Volpato GL. 1993. Heterogeneous growth in the Nile tilapia: social stress and carbohydrate metabolism. Physiol Behav. 54:319-323.

Gonçalves-de-Freitas E, Teresa FB, Gomes FS, Giaquinto PC. 2008. Effect of water renewal on dominance hierarchy of juvenile Nile tilapia. Appl Anim Behav Sci. 112:187-195.

Goodman LA. 1965. On simultaneous confidence intervals for multinomial proportions. Technometrics. 7:247-254.

Johnsson JI, Winberg S, Sloman KA. 2006. Social interactions. In: Sloman KA, Wilson RW, Balshine S, editors. Behaviour and physiology of fish (fish physiology). San Diego (CA): Elsevier; p. 151-196.

Koops M, Grant JWA. 1992. Weight asymmetry and sequential assessment in convict cichlid contests. Can J Zool. 71:475-479.

Maia CM, Volpato GL. 2013. Environmental light color affects the stress response of Nile tilapia. Zoology. 116:64-66.

McKenzie DJ, Höglund E, Dupont-Prinet A, Larsen BK, Skov PV, Pedersen PB, Jokumsen A. 2012. Effects of stocking density and sustained aerobic exercise on growth, energetics and welfare of rainbow trout. Aquaculture. 338:216-222.

Neat FC, Huntingford FA, Beveridge MMC. 1998. Fighting and assessment in male cichlid fish: the effects of asymmetries in gonadal state and body size. Anim Behav. 55:883-891.

Nelissen MHJ. 1985. Structure of the dominance hierarchy and dominance determining "group factors" in Melanochromis auratus (Pisces, Cichlidae). Behaviour. 94:85-107.

Oliveira RF, Almada VC. 1996. On the (in)stability of dominance hierarchies in the cichlid fish Oreochromis mossambicus. Aggressive Behav. 22:37-45.

Pickering AD, Pottinger TG, Christie PJ. 1982. Recovery of the brown trout, Salmo trutta L., from acute handling stress: a time-course study. J Fish Biol. 20:229-244.

Pottinger TG. 2008. The stress response in fish - mechanisms, effects and measurement. In: Branson EJ, editor. Fish welfare. Oxford (UK): Blackwell Publishing Ltd; p. 32-48.

Pottinger TG, Moran T, Morgan J. 1994. Primary and secondary indices of stress in the progeny of rainbow trout (Oncorhynchus mykiss) selected for high and low responsiveness to stress. J Fish Biol. 44:149-163.

Ros AFH, Becker K, Oliveira RF. 2006. Aggressive behaviour and energy metabolism in a cichlid fish, Oreochromis mossambicus. Physiol Behav. 89:164-170.

Schjolden J, Winberg S. 2007. Genetically determined variation in stress responsiveness in rainbow trout: behavior and neurobiology. Brain Behav Evol. 70:227-238.

Slavík O, Pešta M, Horky'. 2011. Effect of grading on energy consumption in European catfish Silurus glanis. Aquaculture. 313:73-78.

Sloman KA, Baker D, Winberg S, Wilson RW. 2008. Are there physiological correlates of dominance in natural trout populations? Anim Behav. 76:1279-1287.

Sloman KA, Motherwell G, O'Connor KI, Taylor AC. 2000. The effect of social stress on the standard metabolic rate (SMR) of brown trout, Salmo trutta. Fish Physiol Biochem. 23: $49-53$.

Sneddon LU, Hawkesworth S, Braithwaite VA, Yerbury J. 2006. Impact of environmental disturbance on the stability and benefits of individual status within dominance hierarchies. Ethology. 112:437-447.

Turner GF, Huntingford FA. 1986. A problem for game theory analysis: assessment and intention in male mouthbrooder contests. Anim Behav. 34:961-970.

Vaz-Serrano J, Ruiz-Gomez ML, Gjøen HM, Skov PV, Huntingford FA, Øverli Ø, Höglund E. 2011. Consistent boldness behaviour in early emerging fry of domesticated Atlantic salmon (Salmo salar): decoupling of behavioural and physiological traits of the proactive stress coping style. Physiol Behav. 103:359-364. 
Verbeek P, Iwamoto T, Murakami N. 2007. Differences in aggression between wild-type and domesticated fighting fish are context dependent. Anim Behav. 73:75-83.

Vollestad LA, Quinn TP. 2003. Trade-off between growth rate and aggression in juvenile coho salmon, Oncorhynchus kisutch. Anim Behav. 66:261-268.

Volpato GL, Barreto RE. 2001. Environmental blue light prevents stress in Nile tilapia. Braz J Med Biol Res. 34:104-1045.

Wendelaar Bonga SE. 1997. The stress response in fish. Physiol Rev. 77:591-625.

Zar J. 1999. Biostatistical analyses. 4th ed. Upper Saddle River (NJ): Prentice Hall. 